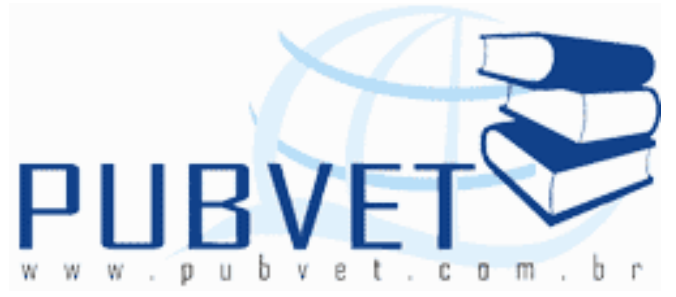

PUBVET, Publicações em Medicina Veterinária e Zootecnia.

Disponível em: <https://doi.org/10.31533/pubvet.v02n10a386>.

\title{
Influência do acabamento de carcaça na composição centesimal do contrafilé ( $m$. Longissimus thoracis) de novilhos nelore
}

\footnotetext{
Sérgio Bertelli Pflanzer ${ }^{1}$, Eduardo K. Pedroso², Pedro E. de Felício ${ }^{3}$

${ }^{1}$ Doutorando em Tecnologia de Alimentos da FEA - UNICAMP

2 Independência Alimentos Ltda

${ }^{3}$ Departamento de Tecnologia de Alimentos da FEA
}

\section{Introdução}

A composição da carcaça é influenciada por muitos fatores como espécie, idade, raça, alimentação e manejo. O tecido muscular pós-rigor livre de gordura aparente apresenta $75 \%$ de água, 19\% de proteína, 2,3\% de substâncias nitrogenadas não-protéicas e minerais, 2,5\% de lipídios, 1,2\% de carboidratos (ácido lático), $1 \%$ de minerais (LAWRIE \& LEDWARD, 2007). O tecido adiposo presente na carne pode constituir depósitos de lipídios subcutâneos, intermusculares, e intramuscular, este último conhecido como marbling ou mármore. Na carne bovina, os teores de proteína (usualmente incluem $\mathrm{N}$ não-protéico) e umidade são inversamente proporcionais ao de lipídios, ou seja, com a deposição de gordura na carcaça deve ocorrer uma redução inicial de umidade e de proteína em seguida.

O acabamento de carcaça, também chamado de gordura de cobertura, é determinado visualmente logo após o abate, ou após o resfriamento, com base numa estimativa da espessura de gordura subcutânea. Essa 
Pflanzer, S.B., Pedroso, E.K. e Felício, P.E. Influência do acabamento de carcaça na composição centesimal do contrafilé ( $\mathrm{m}$. Longissimus thoracis) de novilhos nelore. PUBVET, Londrina, V. 2, N. 40, rt\#386, Out2, 2008.

característica pode influenciar o rendimento de desossa e a qualidade da carne para o consumidor, especialmente aparência, maciez, sabor e suculência.

O objetivo deste estudo foi determinar a influência de dois níveis de acabamento de carcaça na composição centesimal e na porcentagem de água livre do músculo Longissimus thoracis, livre de gordura aparente, obtido do contrafilé de costela de novilhos Nelore.

\section{Material e Métodos}

Carcaças de 60 bovinos foram selecionadas durante o abate de 822 novilhos da raça Nelore de dois e três anos de idade, e agrupadas em 2 categorias, de acordo com o nível de acabamento (2=escasso; $3=$ mediano). A classificação foi realizada por tipificadores treinados. As meias carcaças foram acondicionadas em câmara de resfriamento por 24 h. De cada meia carcaça esquerda foi removida uma porção de aproximadamente $1 \mathrm{Kg}$ de carne da porção cranial do contrafilé, entre a $6^{\mathrm{a}}$ e a $9^{\mathrm{a}}$ costelas.

A composição centesimal das amostras foi determinada em triplicata para teor de umidade, proteínas e cinzas, segundo AOAC (1990), e gordura de acordo com metodologia de Bligh e Dyer (1959). Ainda foi determinado o teor de água livre conforme a metodologia descrita por Wierbicki e Deatherage (1958), que consiste em prensar por 1 minuto uma quantidade conhecida de amostra, sobre um papel filtro entre placas de acrílico, em uma prensa hidráulica até uma pressão $35 \mathrm{kgf} / \mathrm{cm}^{2}$, e medir as áreas do halo interno (área do filme de carne) e externo (área total), para encontrar por diferença a área úmida. Os valores de água livre são encontrados a partir da equação 1 .

Equação 1

$$
\% \mathrm{H}_{2} \mathrm{O}_{\text {livre }}=\frac{\left[\mathrm{A}_{\text {total }}\left(\mathrm{cm}^{2}\right)-\mathrm{A}_{\text {filme }}\left(\mathrm{cm}^{2}\right)\right] \times 9,47}{\text { Umidade total }(\mathrm{mg}) \text { na amostra }} \times 100
$$


Pflanzer, S.B., Pedroso, E.K. e Felício, P.E. Influência do acabamento de carcaça na composição centesimal do contrafilé ( $\mathrm{m}$. Longissimus thoracis) de novilhos nelore. PUBVET, Londrina, V. 2, N. 40, rt\#386, Out2, 2008.

Os dados foram processados pelo programa Statistica 7.0 (STATSOFT, 2005). Foram realizadas análises estatísticas descritiva e de variância (Anova), e as médias foram comparadas pelo teste de Tukey a $5 \%$.

\section{Resultados e Discussão}

As médias de proteína, cinzas e porcentagem de água livre encontram-se na Tabela 1. Observa-se que o teor de cinzas não sofreu efeito $(P>0,05)$ do acabamento de carcaça, mas o de proteína chegou a ser afetado discretamente $(P=0,07)$. Os teores médios de proteínas (inclui $N$-não protéico) e cinzas foram de $22,4 \%$ e $1,0 \%$, respectivamente. Não houve efeito do acabamento no teor de água livre, cujo valor médio foi de $40 \%$.

Tabela 1. Médias e erros padrão da média das porcentagens de proteínas, cinzas e água livre das amostras de contrafilé, agrupadas pelo acabamento de carcaça.

\section{Proteínas (\%) Cinzas (\%) Água livre (\%)}

\section{Acabamento 2}

$(n=30)$

$$
22,63 \pm 0,14 \quad 1,02 \pm 0,01 \quad 39,28 \pm 0,74
$$

Acabamento 3

$(n=30)$

$$
22,29 \pm 0,12 \quad 1,00 \pm 0,01 \quad 41,39 \pm 1,13
$$

$$
P=0,07 \quad P=0,09 \quad P=0,13
$$

Acabamento $2=$ escasso, 1 a $3 \mathrm{~mm}$ sobre o contrafilé; $3=$ mediano, 4 a 6 $\mathrm{mm}$.

$P=$ Nível de significância do teste de F na análise de variância.

Houve efeito $(P<0,05)$ do acabamento de carcaça nos teores de umidade e lipídios (Figura 1), sendo que amostras das carcaças com acabamento mediano tiveram maiores teores de lipídios $(5,8 \%)$ e menores de umidade $(71,2 \%)$, quando comparadas às carcaças com acabamento escasso (umidade, $72,4 \%$ e lipídios 4,2\%). Bruns, Pritchard e Boggs (2004) 
Pflanzer, S.B., Pedroso, E.K. e Felício, P.E. Influência do acabamento de carcaça na composição centesimal do contrafilé ( $\mathrm{m}$. Longissimus thoracis) de novilhos nelore. PUBVET, Londrina, V. 2, N. 40, rt\#386, Out2, 2008.

encontraram diferença significante entre os teores de lipídios, para bifes de L. dorsi provenientes de carcaças com 5 níveis de acabamento; as de maior cobertura apresentavam bifes com $8,2 \%$, enquanto as de menor cobertura tinham $2,6 \%$ de lipídios.

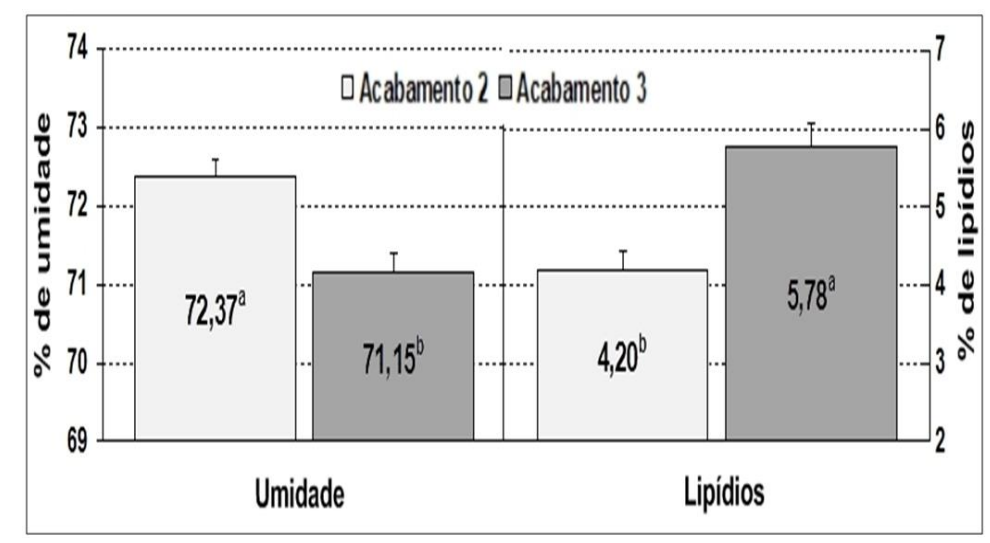

Figura 1. Teores de umidade e lipídios das amostras, de acordo com o acabamento de carcaça. a, b Médias seguidas de letras desiguais diferem $(P<0,05)$.

Uma correlação alta e negativa $(r=-0,92 ; \mathrm{P}<0,05)$ entre $\mathrm{o}$ teor de umidade e lipídios foi encontrada, confirmando resultado obtido por FELÍCIO ( $r=-0,94$; não publicado) que analisou 150 amostras de contrafilé ( $m$. Longissimus dorsi). A implicação disso é que, em estudos futuros, pode-se estimar os teores de lipídios a partir da umidade deste mesmo músculo sem o emprego de reagentes químicos. Para o presente experimento, o cálculo proposto para determinar o teor de lipídios a partir da umidade esta demonstrado na equação 2 .

Equação 2 \% lipídios $=(80,281-1,049) \times \%$ umidade 
Pflanzer, S.B., Pedroso, E.K. e Felício, P.E. Influência do acabamento de carcaça na composição centesimal do contrafilé ( $\mathrm{m}$. Longissimus thoracis) de novilhos nelore. PUBVET, Londrina, V. 2, N. 40, rt\#386, Out2, 2008.

\section{Conclusão}

Os níveis de acabamento escasso e mediano influenciam umidade e lipídios, exercem pouco efeito na proteína, e não afetam as porcentagens de cinzas e água livre do músculo Longissimus thoracis do contrafilé de costela de novilhos Nelore.

\section{Referências}

AOAC - ASSOCIATION OF OFFICIAL ANALYTICAL CHEMISTS. Official methods of analysis. 15. Ed. Washington DC: v.1, p. 99-101, 1990.

BLIGH, E. G.; DYER, W. J. A rapid method of total lípids extraction and purification. Canadian J. of Biochemistry and Physiology, v.37, p. 911-917, 1959.

BRUNS, K. W.; PRITCHARD, R. H.; BOGGS, D. L. The relationships among body weight, body composition, and intramuscular fat content in steers. J. Anim. Sci., v.82, p.13151322, 2004.

LAWRIE, R.A.; LEDWARD, D.A. Lawrie's Meat Science. $7^{\text {th }}$ ed. Woodhead Pub. Ltd., Cambridge, England. 2007. p.76.

STATSOFT. Statistica: data analysis software system, version 7. 2004. CD/ROM.

WIERBICKI, E.; DEATHERAGE, F.E. Determination of water- holding capacity of fresh meats. Agricultural and Food Chemistry, v.6, p.387-392, 1958. 